Communication

\title{
Determination of the Optimal Tilt Angle of Solar Collectors for Different Climates of China
}

\author{
Haixiang Zang *, Mian Guo, Zhinong Wei and Guoqiang Sun \\ College of Energy and Electrical Engineering, Hohai University, Nanjing 211100, China; \\ hhuguomian@163.com (M.G.); znwei@hhu.edu.cn (Z.W.); hhusunguoqiang@163.com (G.S.) \\ * Correspondence: zanghaixiang@hhu.edu.cn; Tel.: +86-25-5809-9081
}

Academic Editor: Marc A. Rosen

Received: 18 May 2016; Accepted: 5 July 2016; Published: 11 July 2016

\begin{abstract}
The tilt angle with the horizon (with respect to the ground) of the solar energy system affects the amount of solar radiation received. This paper suggests a simple and universal method to obtain the optimum tilt angles by estimating the monthly mean daily global solar radiation on tilted surfaces facing directly towards the equator, which is based on monthly average daily global solar radiation data produced from Typical Meteorological Year (TMY) data. The monthly, seasonal, and yearly optimum tilt angles for photovoltaic panels are calculated at six stations of different climatic types (Tropical Zone (TZ), Subtropical Zone (SZ), Warm Temperate Zone (WTZ), Mid Temperate Zone (MTZ), Cold Temperate Zone (CTZ) and Tibetan Plateau Zone (TPZ)). The results indicate that changing the monthly, seasonal, and yearly optimum tilt angles causes a significant yearly gain in the solar radiation for the region. In addition, general correlations are generated to estimate the optimum tilt angle of solar collectors at six typical climatic stations of China. The performances of the proposed models are compared using statistical error tests such as the mean absolute bias error (MABE), the root mean square error (RMSE) and the correlation coefficients (R).
\end{abstract}

Keywords: optimum tilt angle; Typical Meteorological Year; solar radiation; solar energy

\section{Introduction}

The performance of a photovoltaic panel is highly influenced by its tilt angle with the horizontal surface (with respect to the ground) because the tilt angle changes the solar radiation reaching the surface of the collector [1,2]. The best way to collect the maximum daily energy is to use a tracking system. A tracking system is a mechanical device that tracks the sun on its daily sweep across the sky. However, most photovoltaic (PV) modules are not suited for tracking, as they collect more sunlight and, therefore, produce more electricity if they are always oriented toward the sun. Trackers are expensive, need energy for their operation, and are not always applicable. Therefore, it is often practical to orient the solar collector at an optimum tilt angle and to correct the tilt from time to time.

Some investigators have made different recommendations for the optimum tilt, based on the latitude. Lunde [3] and Garg [4] obtained the optimum tilt angle, $\beta_{\mathrm{opt}}, \varphi \pm 15^{\circ}$. Duffie and Beckman [5] obtained $\beta_{\text {opt }},\left(\varphi \pm 15^{\circ}\right) \pm 15^{\circ}$. Ibrahim [6] showed the optimum tilt angles of summer months $\left(\varphi-21^{\circ}\right)$ and winter months $\left(\varphi+13^{\circ}\right)$ for Cyprus. Asl-Soleimani [7] reported an annual optimum tilt angle of $30^{\circ}$, which is a bit lower than the local latitude $\left(35.7^{\circ}\right)$. Kalogirou [8,9] suggested the optimum tilt angle to be $\varphi \pm\left(10^{\circ}-15^{\circ}\right)$. Gunerhan and Hepbasli [10] determined the yearly optimum tilt angle for collectors in Izmir to be $35.8^{\circ}$, which is approximately the location's latitude. Lave and Kleissl [11] suggested yearly optimum tilt angles for several regions of the United States as $\beta_{\text {opt }}, \varphi-\left(1^{\circ}-10^{\circ}\right)$, by calculating the maximum incident solar radiation on the solar collector, where $\varphi$ is the latitude of the location. Jafarkazemi [12] concluded that the yearly optimum tilt angle $\left(\beta_{\text {opt }}=22^{\circ}\right)$ is almost close to the latitude of Abu Dhabi $\left(\varphi=24.4^{\circ}\right)$. 
Some other optimization techniques have also been devoted to this problem in recent years, most of which treat the problem both qualitatively and quantitatively. Abdolzadeh and Mehrabian [13], Bakirci [14,15], and Despotovic [1] estimated the total (global) solar radiation intensity to obtain the optimum slope angle in a specific period for solar collectors. Kaldellis [16,17] and Pourgharibshahi [18] verified the computational optimum tilt angles of a PV module by conducting experiments. The genetic algorithm method $[19,20]$, particle swarm optimization [21,22], and the artificial neural network method $[23,24]$ were also used to estimate the optimum tilt angle of PV modules.

The previous studies on the topic were carried out mostly in the foreign climate and geography. Yang and $\mathrm{Lu}$ [25] developed a new mathematical model for calculating the optimum tilt angles and azimuth angles for building-integrated photovoltaic (BIPV) applications in Hong Kong on yearly, seasonal, and monthly bases. Sun [26] investigated the combined energy effect produced by shading-type BIPV claddings and found that the optimum tilt angles of shading-type BIPV claddings at different orientations provide the most desirable energy-saving effect. Tang [27] theoretically investigated the multi-reflection of radiation on both parabolic reflectors of a compound parabolic concentrator (CPC) with a one-sided flat absorber and its effect on energy-collection calculations. Generally, such research in China is still limited. Thus, the present study aims to develop an analytical procedure to obtain formulae which determine $\beta_{\text {opt }}$ for any climatic type in China.

The main objective of this study is to determine the optimum tilt angle of photovoltaic panels on the basis of maximizing the global solar radiation reaching the collector surface on a monthly, seasonal, and yearly basis and to develop general correlations for estimating the monthly optimum tilt angles at six stations of different climatic zones. The effect of the Earth's reflection on the global solar radiation for a solar collector inclined at the optimum slope angle is investigated. The calculations are based on the data of air-dry bulb temperature, relative humidity, wind velocity, and global solar radiation from China's meteorological stations. These data are collected for a period of 16 years (1994-2009).

\section{Different Climates of China and Optimal Angles Designed for the Six Typical Cities}

China lies in the northeastern part of East Asia and has a complex climate [28,29]. Various methods for classifying the climatic types of China can be found in References [30-32]. In this paper, we use the method which designated China's temperature strip. Accordingly, China is classified into six climatic types, namely the Tropical Zone (TZ), Subtropical Zone (SZ), Warm Temperate Zone (WTZ), Mid Temperate Zone (MTZ), Cold Temperate Zone (CTZ) and Tibetan Plateau Zone (TPZ). Moreover, the zoning criteria are mainly based on the annual accumulated temperature, which is the sum of the daily mean temperature over 10 degrees within a year. Six stations (Sanya, Shanghai, Zhengzhou, Harbin, Mohe, and Lhasa) in China are investigated and generated based on the measured weather data in this paper. General information about the six selected typical stations is shown in Table 1.

Table 1. Geographical locations and weather database for the present study.

\begin{tabular}{ccccccc}
\hline No. & Climate & Location & Latitude (N) & Longitude (E) & Elevation (m) & Period \\
\hline 1 & Tropical Zone (TZ) & Sanya & $18^{\circ} 14^{\prime}$ & $109^{\circ} 31^{\prime}$ & 5.9 & $1994-2009$ \\
2 & Subtropical Zone (SZ) & Shanghai & $31^{\circ} 24^{\prime}$ & $121^{\circ} 29^{\prime}$ & 6 & $1994-2009$ \\
3 & Warm Temperate Zone (WTZ) & Zhengzhou & $34^{\circ} 43^{\prime}$ & $113^{\circ} 39^{\prime}$ & 110.4 & $1994-2009$ \\
4 & Mid Temperate Zone (MTZ) & Harbin & $45^{\circ} 45^{\prime}$ & $126^{\circ} 46^{\prime}$ & 142.3 & $1994-2009$ \\
5 & Cold Temperate Zone (CTZ) & Mohe & $53^{\circ} 28^{\prime}$ & $122^{\circ} 31^{\prime}$ & 433 & $1994-2009$ \\
6 & Tibetan Plateau Zone (TPZ) & Lhasa & $29^{\circ} 40^{\prime}$ & $91^{\circ} 08^{\prime}$ & 3648.7 & $1994-2009$ \\
\hline
\end{tabular}




\section{Development of Monthly Mean Daily Global Solar Radiation Data}

\subsection{Data Used}

In this work, the measured weather data (including daily maximum, minimum, and mean air-dry bulb temperature; daily minimum and mean relative humidity; daily maximum and mean wind velocity; and daily global solar radiation data) for the six stations are gathered from China's meteorological stations. The missing and invalid measured weather data for the six stations shown in Table 1 are marked and coded as 32,744 or 32,766 in the original document of China's meteorological stations. In addition, the questionable data are replaced by the values of previous or subsequent days using the interpolation method [33].

\subsection{Method and Process for Forming Monthly Mean Daily Global Solar Radiation Data}

Monthly mean daily global solar radiation data are the basic and key parameters in the following process of forming the optimal tilt angle. Since solar radiation data can vary from year to year, there is a need to generate a customized solar radiation database that can well represent the long-term averaged solar radiation over a year [31,34-37]. In this subsection, the Typical Meteorological Year (TMY) method is recommended and applied. The TMY method is the methodology for combining 12 typical meteorological months (TMMs) from different years of the measured period to form a complete year. The selection procedure of the 12 TMMs consists of two steps:

Step 1: Selection of five candidate years. The cumulative distribution function (CDF) for each weather index is determined by the following function:

$$
S_{n}(x)=\left\{\begin{array}{ccc}
0 & \text { for } & x<x_{1} \\
(i-0.5) / n & \text { for } & x_{i} \leqslant x<x_{i+1} \\
1 & \text { for } & x \geqslant x_{n}
\end{array}\right.
$$

where $S_{n}(x)$ is the value of the CDF for weather index $x ; n$ is the total number of elements; $i$ is the rank order number $(i=1,2,3, \ldots, n-1)$. Next, the values of Finkelstein-Schafer (FS) statistics [38] for each weather index are calculated by the equation:

$$
F S_{x}(y, m)=\frac{1}{N} \sum_{i=1}^{N}\left|C D F_{m}\left(x_{i}\right)-C D F_{y, m}\left(x_{i}\right)\right|
$$

where $F S_{x}(y, m)$ is the FS statistic for the year $y$, month $m ; C D F_{m}$ is the long-term and $C D F_{y, m}$ is the short-term (for the year $y$ ) cumulative distribution function of the weather index $x$ for month $m ; N$ is the number of daily readings of the month.

The weighted sum (WS) of the FS statistics for the above eight meteorological indices is then calculated for each year. In addition, the five years are selected as the candidate years having the smallest WS values. The WS is defined as follows:

$$
W S(y, m)=\frac{1}{M} \sum_{x=1}^{M} W F_{x} \cdot F S_{x}(y, m)
$$

where $W S(y, m)$ is the average weighted sum for the month $m$ in the year $y$; WF $F_{\mathbf{x}}$ is the weighting factor for the $x$ th weather index (shown in Table 2); $M$ is the number of meteorological parameter indices (eight in this paper). 
Table 2. Meteorological indices and weighting factors $\left(W F_{x}\right)$ for the FS statistic in this study.

\begin{tabular}{cccc}
\hline Number & & Parameter Indices & Present Article \\
\hline 1 & Temperature & Max Dry Bulb Temperature & $1 / 24$ \\
2 & & Min Dry Bulb Temperature & $1 / 24$ \\
3 & & Mean Dry Bulb Temperature & $3 / 24$ \\
4 & Humidity & Min Relative Humidity & $1 / 24$ \\
5 & & Mean Relative Humidity & $2 / 24$ \\
6 & Wind & Max Wind Velocity & $2 / 24$ \\
7 & & Mean Wind Velocity & $2 / 24$ \\
8 & Solar radiation & Global Solar Radiation & $12 / 24$ \\
\hline
\end{tabular}

Step 2: Final selection of TMM. The final step is to choose TMMs from the five candidate years. The month with the minimum root mean square difference (RMSD) [39] of global solar radiation is chosen as the TMM. The TMM is calculated according to:

$$
R M S D=\left[\frac{\sum_{i=1}^{N}\left(H_{y, m, i}-H_{m a}\right)^{2}}{N}\right]^{1 / 2}
$$

where $H_{y, m, i}$ is the daily global solar radiation values of the year $y$, month $m$ and day $i ; H_{m a}$ is the mean values of the long-term global solar radiation for the month $m ; N$ is the number of daily readings of the month.

The TMY data and typical global solar radiation data for the six stations listed in Table 1 are investigated and generated based on the above measured weather data and the TMY method. The detailed generation process for the TMY data can be found in our previous research [39]. In addition, the TMY data of the six stations in different climatic zones of China produced in Reference [39] are shown in Table 3.

By applying the daily mean global solar radiation data, the monthly mean daily global solar radiation data of the six stations in six different climatic zones of China are computed and formed based on the corresponding TMY data. The monthly mean daily global solar radiation data of the six stations are given in Table 3. 
Table 3. Summary of TMYs selected and the corresponding monthly average daily global solar radiation (MJ $\left./ \mathrm{m}^{2}\right)$ for the six stations in different climatic zones of China.

\begin{tabular}{|c|c|c|c|c|c|c|c|c|c|c|c|c|c|}
\hline \multirow{2}{*}{ Climate } & \multirow{2}{*}{ Station } & \multicolumn{12}{|c|}{ Month } \\
\hline & & January & February & March & April & May & June & July & August & September & October & November & December \\
\hline \multirow{2}{*}{$\mathrm{TZ}$} & \multirow{2}{*}{ Sanya } & 2002 & 2002 & 2001 & 2003 & 1998 & 2000 & 2000 & 2002 & 2004 & 1995 & 2002 & 2004 \\
\hline & & 14.06 & 15.28 & 15.73 & 19.29 & 19.96 & 18.59 & 17.58 & 19.42 & 16.64 & 16.12 & 14.71 & 12.58 \\
\hline \multirow{2}{*}{$\mathrm{SZ}$} & \multirow{2}{*}{ Shanghai } & 1997 & 1997 & 2004 & 2008 & 1996 & 1998 & 1998 & 2004 & 2003 & 1997 & 1999 & 1998 \\
\hline & & 7.41 & 11.15 & 12.74 & 13.80 & 17.27 & 15.05 & 19.60 & 17.95 & 15.21 & 11.66 & 8.08 & 7.79 \\
\hline \multirow[b]{2}{*}{ WTZ } & \multirow{2}{*}{ Zhengzhou } & 1996 & 1998 & 1995 & 2006 & 2000 & 1997 & 2002 & 2002 & 2001 & 2008 & 1998 & 1998 \\
\hline & & 6.81 & 10.19 & 13.90 & 16.06 & 19.85 & 17.96 & 17.30 & 16.94 & 13.33 & 10.69 & 8.90 & 7.13 \\
\hline \multirow{2}{*}{ MTZ } & \multirow{2}{*}{ Harbin } & 2003 & 1998 & 2004 & 1996 & 2001 & 1995 & 1998 & 2009 & 2004 & 2004 & 2009 & 1996 \\
\hline & & 5.59 & 9.31 & 13.79 & 16.00 & 19.87 & 21.61 & 19.81 & 17.09 & 14.55 & 10.00 & 6.27 & 4.56 \\
\hline \multirow{2}{*}{$\mathrm{CTZ}$} & \multirow{2}{*}{ Mohe } & 2003 & 2000 & 2006 & 2003 & 2004 & 1999 & 2006 & 2006 & 2007 & 2005 & 2005 & 2004 \\
\hline & & 3.94 & 9.27 & 13.54 & 16.51 & 17.05 & 23.65 & 20.26 & 16.92 & 12.83 & 7.69 & 4.49 & 3.04 \\
\hline \multirow{2}{*}{$\mathrm{TPZ}$} & \multirow{2}{*}{ Lhasa } & 2001 & 1999 & 2008 & 2008 & 1994 & 2002 & 1999 & 2005 & 2001 & 2000 & 2001 & 2001 \\
\hline & & 15.60 & 17.82 & 20.35 & 22.87 & 25.30 & 26.19 & 22.67 & 21.35 & 21.20 & 19.63 & 17.64 & 15.03 \\
\hline
\end{tabular}




\section{Estimation of Solar Radiation on the Inclined Surface}

The monthly mean daily global solar radiation data on the inclined surface are important and useful for solar energy applications. However, daily global solar radiation data on a tilted surface are generally unmeasured and unavailable. In this paper, a simple and universal method is proposed to estimate the monthly mean daily global solar radiation on tilted surfaces facing directly towards the equator. Moreover, the monthly mean daily global radiation on a tilted surface $\left(H_{T}\right)$ can be estimated by the following relation:

$$
H_{T}=R H
$$

where $R$ is the ratio of the monthly average daily global radiation on a tilted surface to that on a horizontal surface. The ratio $R$, developed by Liu and Jordan $[15,40]$, can be defined as:

$$
R=\left(1-\frac{H_{d}}{H}\right) R_{b}+\frac{H_{d}}{H}\left(\frac{1+\cos \beta}{2}\right)+\rho\left(\frac{1-\cos \beta}{2}\right)
$$

where $H$ and $H_{d}$ are the monthly average daily global and diffuse solar radiation on a horizontal surface, respectively; $R_{b}$ is the ratio of the average daily beam radiation for each calendar month on an inclined surface to that on a horizontal surface; $\rho(=0.2)$ is the ground reflection coefficient; $\beta$ is the tilt angle of photovoltaic panels. The monthly average daily global solar radiation data produced from the TMY data, proposed in our earlier research [39], are applied in the present study.

The diffuse component recommended in the previous studies [41] is adopted in this work. Accordingly, the monthly average daily diffuse solar radiation data is calculated according to:

$$
H_{d}=H\left(1.00-1.13 K_{T}\right)
$$

where $K_{T}$ is the clearness index of the sky. $K_{T}$ can be obtained using the following formula:

$$
K_{T}=H / H_{0}
$$

Here, $H_{0}$ is the monthly mean daily extraterrestrial radiation on a horizontal surface [42], which is computed by

$$
H_{0}=\frac{24 \times 3600}{\pi} \cdot I_{0} \cdot\left(1+0.033 \cos \frac{360 n}{365}\right) \cdot\left(\cos j \cos \delta \sin \omega_{s}+\frac{2 \pi \omega_{s}}{360} \sin j \sin \delta\right)
$$

where $I_{0}$ is the solar constant $\left(1367 \mathrm{~W} / \mathrm{m}^{2}\right) ; n$ is the number of daily readings of the month and is counted from 1 January (1-365); $j$ is the geographic latitude of the location; $\omega_{S}$ is the sunrise (or sunset) angle on a horizontal surface; $\delta$ is the declination of the sun. In this paper, the monthly representative day and its corresponding declination are applied and shown in Table 4.

Table 4. Monthly representative day and its corresponding declination ( $\delta)$.

\begin{tabular}{ccccccc}
\hline Month & January & February & March & April & May & June \\
\hline Day $(n)$ & 17 & 47 & 75 & 105 & 135 & 162 \\
Declination $(\delta)$ & -20.92 & -12.95 & -2.43 & 9.41 & 18.79 & 23.09 \\
\hline Month & July & August & September & October & November & December \\
\hline Day $(n)$ & 198 & 228 & 258 & 288 & 318 & 344 \\
Declination $(\delta)$ & 21.18 & 13.46 & 2.22 & -9.60 & -18.91 & -23.05 \\
\hline
\end{tabular}


In the present study, the photovoltaic panels are all in the Northern Hemisphere, and the factor $R_{b}$ suggested by Liu and Jordan [40] can be written as

$$
R_{b}=\frac{\cos (j-\beta) \cos \delta \sin \omega_{s}{ }^{\prime}+(\pi / 180) \omega_{s}{ }^{\prime} \sin (j-\beta) \sin \delta}{\cos j \cos \delta \sin \omega_{s}+(\pi / 180) \omega_{s} \sin j \sin \delta}
$$

where $\omega_{S}^{\prime}$ is the sunrise (or sunset) hour angle for the inclined surface.

In this paper, Equations (5)-(10) are applied to calculate the monthly mean daily global solar radiation on the south-facing inclined surface for six different stations in China. The tilt angle is changed from $-20^{\circ}$ to $90^{\circ}$ in steps of $0.1^{\circ}$ and the corresponding value of maximum global solar radiation for a specific period is defined as the optimal tilt angle.

\section{Results and Discussions}

By applying the above procedure and the data from the six stations listed in Table 1, the monthly, seasonal, and yearly optimum tilt angles and total radiation on the inclined panel are calculated using Equations (5)-(10).

Table 5 shows the monthly optimum tilt angle of the six stations. The monthly optimum angles range from $-14.7^{\circ}$ (June) to $43.3^{\circ}$ (December) for Sanya, from $-5.2^{\circ}$ (June) to $53.2^{\circ}$ (December) for Shanghai, from $-3.9^{\circ}$ (June) to $57^{\circ}$ (December) for Zhengzhou, from $2.6^{\circ}$ (June) to $69.4^{\circ}$ (December) for Harbin, from $9.3^{\circ}$ (June) to $78.4^{\circ}$ (December) for Mohe, and from $-8.5^{\circ}$ (June) to $60.5^{\circ}$ (December) for Lhasa. Obviously, negative values appear in the determination of optimum tilt angles, such as for June in Lhasa. A negative value of the optimum tilt angle indicates that the photovoltaic panels face North.

Taking Harbin as an example, the calculated data generated by the above method are given in Table 6, including the monthly mean daily extraterrestrial radiation on a horizontal surface $\left(H_{0}\right)$, the clearness index of the sky $\left(K_{T}\right)$, diffuse solar radiation on a horizontal surface $\left(H_{d}\right)$, the optimum tilt angle $\left(\beta_{\text {opt }}\right)$, the monthly mean daily global solar radiation on an optimum tilt surface $\left(H_{T}\right)$, and the comparison of $H$ and $H_{T}$. Clearly, the maximum and minimum $H_{T}$ values occur in June and December, respectively. Meanwhile, it can be seen from Table 6 (the last column) that the efficiency of the solar panel at the monthly optimum tilt angle is obviously increased compared to that with a horizontal surface. Within a year, the comparison of $H$ and $H_{T}$ has a maximum value of $120.95 \%$ (December). 
Table 5. Monthly, seasonal, and yearly optimum tilt angles for six selected stations.

\begin{tabular}{|c|c|c|c|c|c|c|c|c|c|c|c|c|c|}
\hline \multirow{2}{*}{ Station } & \multirow{2}{*}{ Period } & \multicolumn{12}{|c|}{ Month } \\
\hline & & January & February & March & April & May & June & July & August & September & October & November & December \\
\hline \multirow{3}{*}{ Sanya (TZ) } & Monthly & 42.9 & 32.5 & 17.4 & 2.7 & -9.7 & -14.7 & -11.6 & -2.8 & 11.9 & 27.8 & 39.9 & 43.3 \\
\hline & Seasonal & 39.6 & 39.6 & 3.5 & 3.5 & 3.5 & -9.7 & -9.7 & -9.7 & 26.5 & 26.5 & 26.5 & 39.6 \\
\hline & Yearly & 15.0 & 15.0 & 15.0 & 15.0 & 15.0 & 15.0 & 15.0 & 15.0 & 15.0 & 15.0 & 15.0 & 15.0 \\
\hline \multirow{3}{*}{ Shanghai (SZ) } & Monthly & 49.1 & 43.1 & 27.4 & 11.6 & -0.3 & -5.2 & -3.5 & 7.4 & 23 & 37.6 & 46.6 & 53.2 \\
\hline & Seasonal & 48.6 & 48.6 & 12.9 & 12.9 & 12.9 & -0.4 & -0.4 & -0.4 & 35.7 & 35.7 & 35.7 & 48.6 \\
\hline & Yearly & 24.2 & 24.2 & 24.2 & 24.2 & 24.2 & 24.2 & 24.2 & 24.2 & 24.2 & 24.2 & 24.2 & 24.2 \\
\hline \multirow{3}{*}{ Zhengzhou (WTZ) } & Monthly & 53.1 & 46 & 32.3 & 15.6 & 2.2 & -3.9 & -1.3 & 9.8 & 24.6 & 40.3 & 53.3 & 57 \\
\hline & Seasonal & 52.0 & 52.0 & 16.7 & 16.7 & 16.7 & 1.5 & 1.5 & 1.5 & 39.4 & 39.4 & 39.4 & 52.0 \\
\hline & Yearly & 27.4 & 27.4 & 27.4 & 27.4 & 27.4 & 27.4 & 27.4 & 27.4 & 27.4 & 27.4 & 27.4 & 27.4 \\
\hline \multirow{4}{*}{ Harbin (MTZ) } & Monthly & 68.2 & 60.5 & 45.9 & 26 & 11 & 2.6 & 6.3 & 19.2 & 38.2 & 54.8 & 65.4 & 69.4 \\
\hline & Seasonal & 66.0 & 66.0 & 27.6 & 27.6 & 27.6 & 9.4 & 9.4 & 9.4 & 52.8 & 52.8 & 52.8 & 66.0 \\
\hline & Yearly & 39.0 & 39.0 & 39.0 & 39.0 & 39.0 & 39.0 & 39.0 & 39.0 & 39.0 & 39.0 & 39.0 & 39.0 \\
\hline & Monthly & 76.9 & 71.2 & 56.2 & 35 & 15.9 & 9.3 & 12.4 & 26.5 & 46.1 & 62.8 & 74.3 & 78.4 \\
\hline \multirow[t]{2}{*}{ Mohe (MTZ) } & Seasonal & 75.5 & 75.5 & 35.7 & 35.7 & 35.7 & 16.1 & 16.1 & 16.1 & 61.1 & 61.1 & 61.1 & 75.5 \\
\hline & Yearly & 47.1 & 47.1 & 47.1 & 47.1 & 47.1 & 47.1 & 47.1 & 47.1 & 47.1 & 47.1 & 47.1 & 47.1 \\
\hline \multirow{3}{*}{ Lhasa (TPZ) } & Monthly & 58.5 & 48.3 & 32.2 & 13.9 & -1.7 & -8.5 & -5 & 6.8 & 25.2 & 43.7 & 56.5 & 60.5 \\
\hline & Seasonal & 55.8 & 55.8 & 14.8 & 14.8 & 14.8 & -2.2 & -2.2 & -2.2 & 41.8 & 41.8 & 41.8 & 55.8 \\
\hline & Yearly & 27.5 & 27.5 & 27.5 & 27.5 & 27.5 & 27.5 & 27.5 & 27.5 & 27.5 & 27.5 & 27.5 & 27.5 \\
\hline
\end{tabular}


Table 6. $H_{0}, K_{T}, H_{d}, \beta_{\mathrm{opt}}, H_{T}$, and comparison with $H$ of Harbin.

\begin{tabular}{|c|c|c|c|c|c|c|}
\hline Month & $H_{0}\left(\mathrm{MJ} / \mathrm{m}^{2}\right)$ & $K_{T}$ & $H_{d}\left(\mathrm{MJ} / \mathrm{m}^{2}\right)$ & $\beta_{\text {opt }}\left({ }^{\circ}\right)$ & $H_{T}\left(\mathrm{MJ} / \mathrm{m}^{2}\right)$ & $\begin{array}{c}\text { The Comparison } \\
H_{T} \text { with } H(\%)\end{array}$ \\
\hline January & 11.13 & 0.50 & 2.42 & 68.2 & 12.06 & 115.69 \\
\hline February & 16.40 & 0.57 & 3.34 & 60.5 & 16.22 & 74.21 \\
\hline March & 24.57 & 0.56 & 5.04 & 45.9 & 18.12 & 31.42 \\
\hline April & 32.09 & 0.50 & 6.98 & 26 & 17.18 & 7.39 \\
\hline May & 40.47 & 0.49 & 8.84 & 11 & 20.08 & 1.04 \\
\hline June & 41.78 & 0.52 & 8.98 & 2.6 & 21.62 & 0.05 \\
\hline July & 42.91 & 0.46 & 9.48 & 6.3 & 19.87 & 0.30 \\
\hline August & 36.43 & 0.47 & 8.03 & 19.2 & 17.70 & 3.58 \\
\hline September & 26.95 & 0.54 & 5.67 & 38.2 & 17.33 & 19.13 \\
\hline October & 19.37 & 0.52 & 4.16 & 54.8 & 15.08 & 50.80 \\
\hline November & 13.02 & 0.48 & 2.86 & 65.4 & 12.18 & 94.23 \\
\hline December & 10.25 & 0.45 & 2.27 & 69.4 & 10.27 & 120.95 \\
\hline
\end{tabular}

The monthly total global solar radiation, when the tilt angle changes from $-20^{\circ}$ to $90^{\circ}$, is given in Figure 1. The figure indicates that for each month, there is a great difference among the monthly total global solar radiation values due to different tilt angles. In addition, the maximum value of the monthly total global solar radiation corresponds to a specific tilt angle, i.e., the monthly optimum tilt angle. For October, the maximum value of the monthly total global solar radiation for Harbin (MTZ) is $467.48 \mathrm{MJ} / \mathrm{m}^{2}$, corresponding to $54.8^{\circ}$ (the monthly optimum tilt angle).
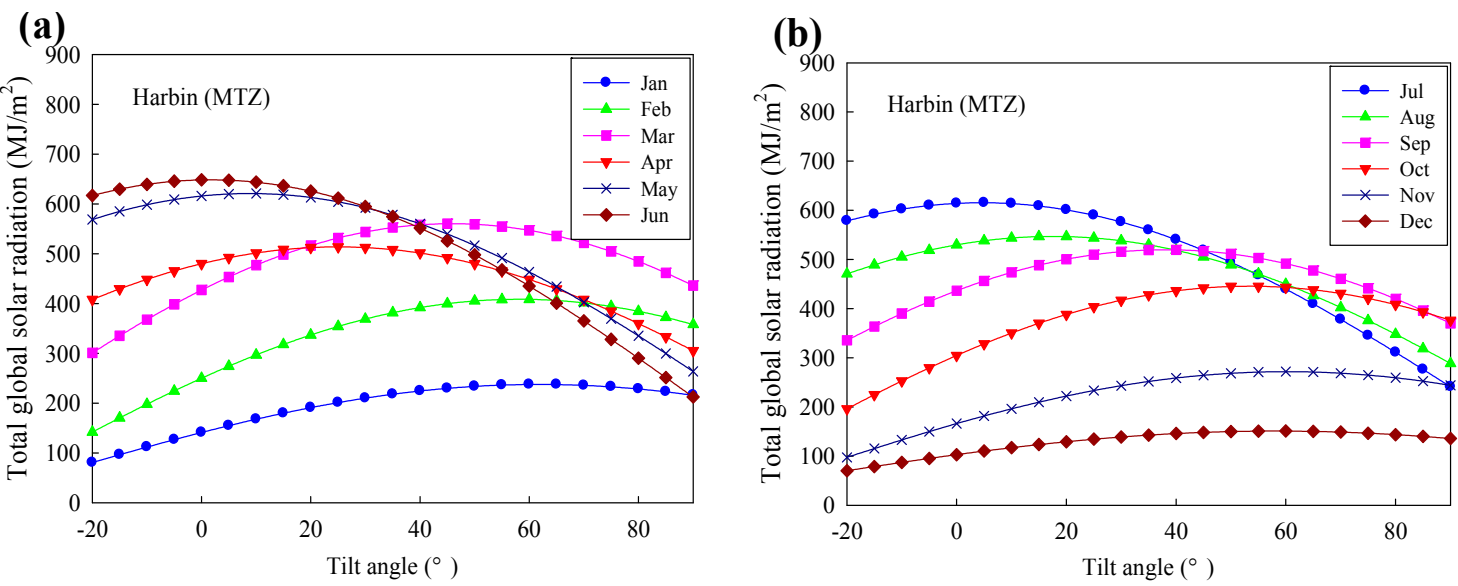

Figure 1. Monthly total global solar radiation data (Harbin) when the tilt angle changes from $-20^{\circ}$ to $90^{\circ}$, (a) January-June and (b) July-December.

Figure 2 shows the total global solar radiation for the determined tilt angles when the solar collector is tilted at the monthly optimum tilt angle, the latitude, and the latitude \pm 15 . Results reveal that the optimum angles give higher values of the optimum angle for the whole year as compared with the latitude and the latitude \pm 15 . It is noted that in March, there is little difference in the radiation values determined by these methods. 


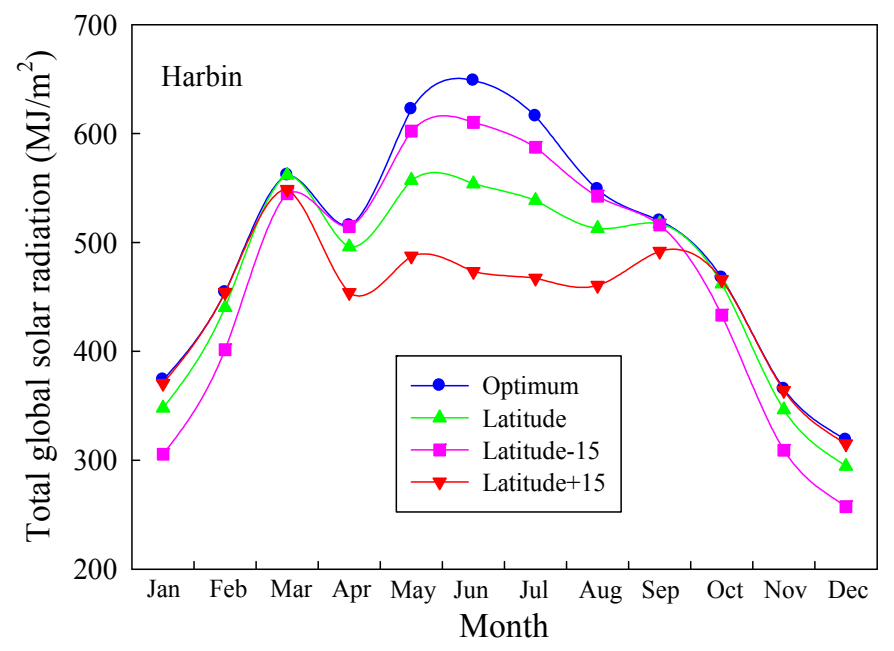

Figure 2. Total global solar radiation (Harbin) for determined tilt angles.

The seasonal and yearly optimum tilt angles for six stations in different climatic zones are also given in Table 5. The seasonal optimum tilt angles are the mean of the monthly optimum tilt angles in a season, while the yearly optimum tilt angles are the average of the monthly optimum tilt angles in a year. Figure 3 shows the mean daily global solar radiation collected fixed at zero and at optimum monthly, optimum seasonal, and optimum yearly tilt angles for each month at six stations. As shown in the figure, the mean daily global solar radiation on a solar collector fixed at the monthly optimum tilt angle shows a significant increase compared to the horizontal and yearly collectors. Moreover, the mean daily global solar radiation at the optimum tilt angle is generally more than that for the horizontal collector, especially in the spring and winter at the Zhengzhou (WTZ), Harbin (MTZ), Mohe (CTZ), and Lhasa (TPZ) stations.

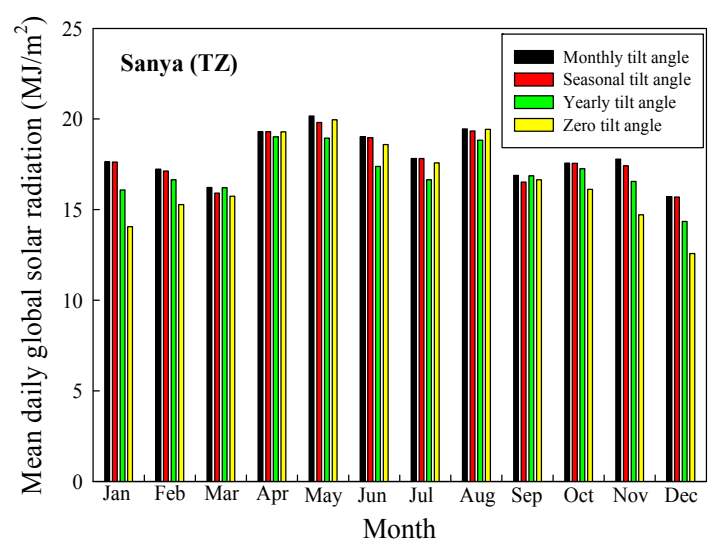

(a)

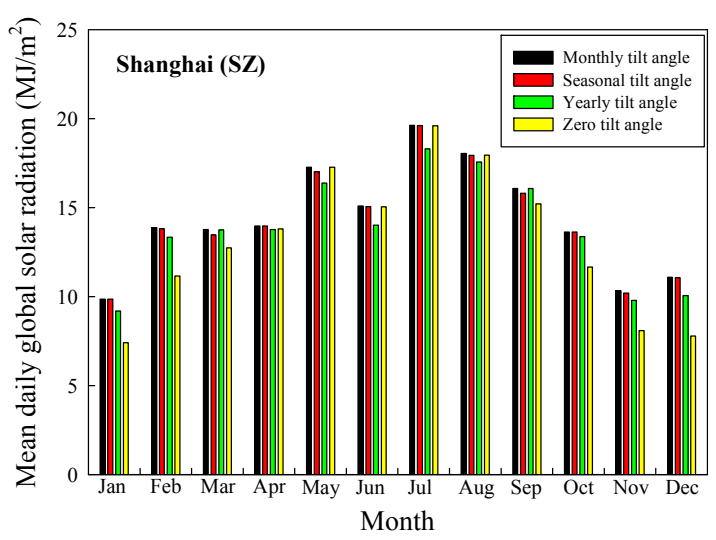

(b)

Figure 3. Cont. 


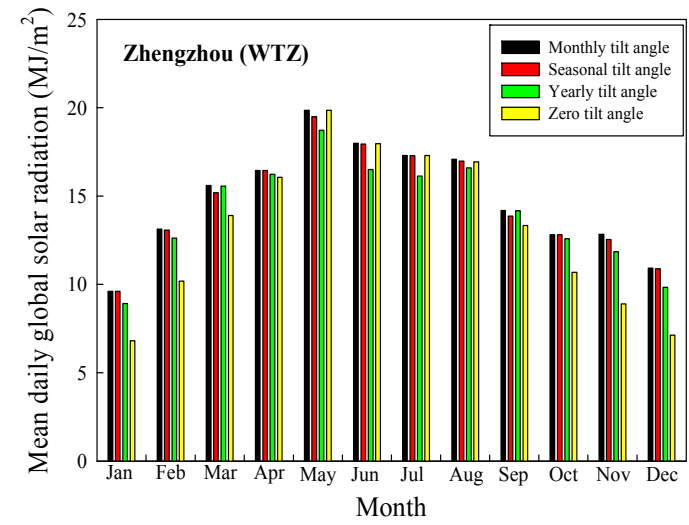

(c)

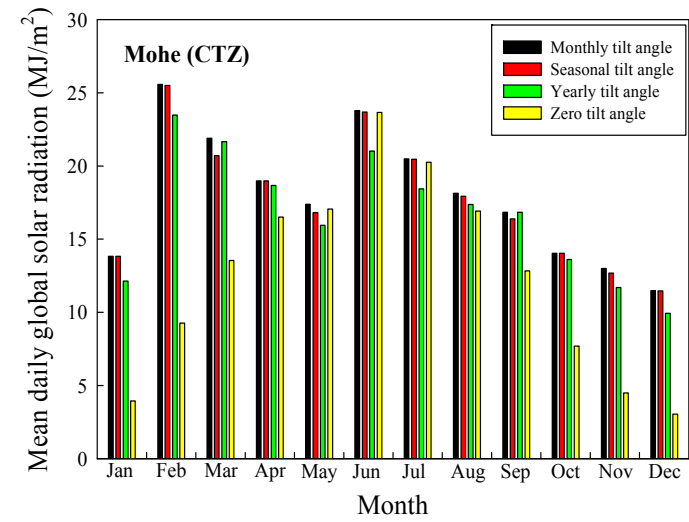

(e)

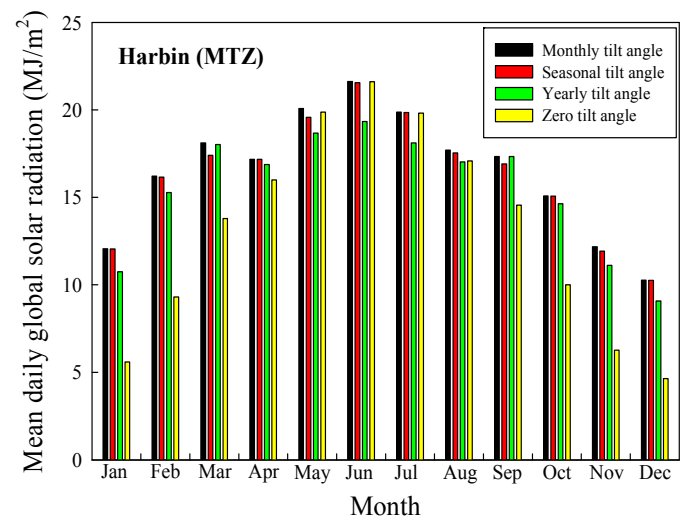

(d)

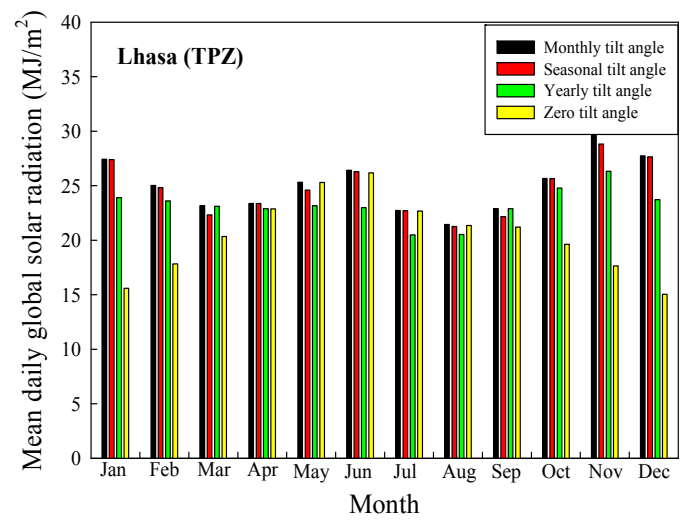

(f)

Figure 3. Comparison between the monthly mean daily solar radiation on a solar collector fixed at zero and at optimum monthly, optimum seasonal, and optimum yearly tilt angles at six different climatic stations. (a) Sanya (TZ); (b) Shanghai (SZ); (c) Zhengzhou (WTZ); (d) Harbin (MTZ); (e) Mohe (CTZ); (f) Lhasa (TPZ).

Additionally, the correlation equations of the optimum tilt angle $\left(\beta_{\mathrm{opt}}\right)$ based on the declination factor $(\delta)$ are generated and investigated for six stations in different climatic zones of China. These correlation equations are given below, where $a, b, c, d$ are the regression coefficients of $\delta$ from degree 0 (constant term) to degree 3 , respectively.

$$
\begin{gathered}
\beta_{o p t}=a-b \cdot(\delta) \\
\beta_{o p t}=a-b \cdot(\delta)-c \cdot(\delta)^{2} \\
\beta_{o p t}=a-b \cdot(\delta)-c \cdot(\delta)^{2}-(d) \cdot \delta^{3}
\end{gathered}
$$

The accuracy and suitability of the models is checked by the mean absolute bias error (MABE), the root mean square error (RMSE) and the correlation coefficient (R) [43-45]. The values of $\beta_{\text {opt }}$ calculated from the above equations obtained for each station are presented in Table 7 . The regression coefficients and the statistical errors of the proposed equations for the six stations in different climates of China are shown in Table 8. The MABE lies between $0.2221 \mathrm{MJ} / \mathrm{m}^{2}$ and $2.5413 \mathrm{MJ} / \mathrm{m}^{2}$, the maximum of RMSE is $2.8892 \mathrm{MJ} / \mathrm{m}^{2}$ and the minimum of RMSE is $0.2697 \mathrm{MJ} / \mathrm{m}^{2}$. Also, the mean value of the correlation coefficients $\mathrm{R}$ for all the six stations is as high as 0.9983 . The results indicate that the monthly optimum tilt angle data obtained from the proposed models are sufficiently reliable. According to the results of the statistical indicators, Equation (13) generally has the best performance when compared with Equations (11) and (12). 
Table 7. The values of the monthly optimum tilt angle (in degrees) calculated from correlations obtained for each station.

\begin{tabular}{|c|c|c|c|c|c|c|c|c|c|c|c|c|c|}
\hline \multirow{2}{*}{ Station } & \multirow{2}{*}{ Equation } & \multicolumn{12}{|c|}{ Month } \\
\hline & & January & February & March & April & May & June & July & August & September & October & November & December \\
\hline \multirow{3}{*}{$\begin{array}{c}\text { Sanya } \\
\text { (TZ) }\end{array}$} & (11) & 42.0 & 31.7 & 18.1 & 2.8 & -9.3 & -14.8 & -12.4 & -2.4 & 12.1 & 27.4 & 39.4 & 44.8 \\
\hline & (12) & 42.1 & 31.7 & 18.1 & 2.8 & -9.3 & -14.8 & -12.3 & -2.4 & 12.1 & 27.4 & 39.5 & 44.8 \\
\hline & (13) & 41.9 & 32.3 & 18.2 & 2.3 & -9.4 & -14.2 & -12.2 & -2.9 & 11.9 & 27.9 & 39.6 & 44.3 \\
\hline \multirow{3}{*}{$\begin{array}{l}\text { Shanghai } \\
\text { (SZ) }\end{array}$} & (11) & 50.8 & 40.7 & 27.3 & 12.2 & 0.3 & -5.1 & -2.7 & 7.1 & 21.4 & 36.4 & 48.2 & 53.5 \\
\hline & (12) & 50.2 & 41.0 & 28.2 & 12.9 & 0.0 & -6.1 & -3.3 & 7.4 & 22.3 & 37.0 & 47.9 & 52.5 \\
\hline & (13) & 50.0 & 41.6 & 28.4 & 12.3 & -0.2 & -5.5 & -3.2 & 6.8 & 22.1 & 37.6 & 48.0 & 52.0 \\
\hline \multirow{3}{*}{$\begin{array}{l}\text { Zhengzhou } \\
\text { (WTZ) }\end{array}$} & (11) & 55.2 & 44.6 & 30.7 & 15.0 & 2.5 & -3.2 & -0.6 & 9.6 & 24.5 & 40.2 & 52.5 & 58.0 \\
\hline & (12) & 54.5 & 45.0 & 31.6 & 15.6 & 2.2 & -4.1 & -1.3 & 9.9 & 25.5 & 40.8 & 52.2 & 57.0 \\
\hline & (13) & 54.4 & 45.3 & 31.7 & 15.3 & 2.1 & -3.8 & -1.2 & 9.6 & 25.4 & 41.1 & 52.3 & 56.7 \\
\hline \multirow{3}{*}{$\begin{array}{c}\text { Harbin } \\
\text { (MTZ) }\end{array}$} & (11) & 69.7 & 58.0 & 42.5 & 25.2 & 11.4 & 5.1 & 7.8 & 19.2 & 35.7 & 53.1 & 66.8 & 72.9 \\
\hline & (12) & 68.0 & 59.0 & 45.2 & 27.0 & 10.5 & 2.3 & 6.0 & 20.1 & 38.4 & 54.9 & 65.8 & 70.1 \\
\hline & (13) & 67.8 & 59.7 & 45.4 & 26.3 & 10.3 & 3.0 & 6.2 & 19.5 & 38.2 & 55.6 & 66.0 & 69.5 \\
\hline \multirow{3}{*}{$\begin{array}{l}\text { Mohe } \\
\text { (MTZ) }\end{array}$} & (11) & 79.3 & 67.1 & 50.8 & 32.6 & 18.2 & 11.6 & 14.5 & 26.4 & 43.7 & 61.9 & 76.3 & 82.6 \\
\hline & (12) & 77.0 & 68.4 & 54.4 & 35.1 & 17.0 & 8.0 & 12.1 & 27.6 & 47.3 & 64.3 & 75.0 & 79.0 \\
\hline & (13) & 76.8 & 69.3 & 54.7 & 34.2 & 16.8 & 8.8 & 12.3 & 26.7 & 47.0 & 65.1 & 75.2 & 78.1 \\
\hline \multirow{3}{*}{$\begin{array}{l}\text { Lhasa } \\
\text { (TPZ) }\end{array}$} & (11) & 59.4 & 47.3 & 31.3 & 13.2 & -1.0 & -7.6 & -4.7 & 7.1 & 24.2 & 42.2 & 56.4 & 62.7 \\
\hline & (12) & 58.6 & 47.7 & 32.5 & 14.1 & -1.4 & -8.8 & -5.5 & 7.5 & 25.4 & 43.0 & 55.9 & 61.4 \\
\hline & (13) & 58.4 & 48.3 & 32.7 & 13.5 & -1.6 & -8.2 & -5.3 & 6.9 & 25.3 & 43.6 & 56.1 & 60.8 \\
\hline
\end{tabular}


Table 8. Regression coefficients and statistical indicators (MABE, RMSE, R) of Equations (11)-(13) at six different climatic stations.

\begin{tabular}{|c|c|c|c|c|c|c|c|c|}
\hline Station & Equation & $a$ & $b$ & $c$ & $d$ & $\begin{array}{c}\text { MABE } \\
\left(\mathrm{MJ} / \mathrm{m}^{2}\right)\end{array}$ & $\begin{array}{l}\text { RMSE } \\
\left(\mathrm{MJ} / \mathrm{m}^{2}\right)\end{array}$ & $\mathbf{R}$ \\
\hline \multirow{3}{*}{ Sanya (TZ) } & (11) & 14.9988 & 1.2923 & - & - & 0.5665 & 0.6751 & 0.9995 \\
\hline & (12) & 14.9353 & 1.2924 & -0.0002 & - & 0.5491 & 0.6736 & 0.9995 \\
\hline & (13) & 14.9307 & 1.3636 & -0.0002 & -0.0002 & 0.4429 & 0.5489 & 0.9997 \\
\hline \multirow{3}{*}{ Shanghai (SZ) } & (11) & 24.1982 & 1.2704 & - & - & 0.9491 & 1.1931 & 0.9995 \\
\hline & (12) & 25.1463 & 1.2699 & 0.0036 & - & 0.8186 & 0.9829 & 0.9989 \\
\hline & (13) & 25.1413 & 1.3460 & 0.0036 & -0.0002 & 0.7523 & 0.8901 & 0.9991 \\
\hline \multirow{3}{*}{ Zhengzhou (WTZ) } & (11) & 27.4496 & 1.3257 & - & - & 0.8056 & 1.0048 & 0.9995 \\
\hline & (12) & 28.4550 & 1.3252 & 0.0038 & - & 0.5101 & 0.7036 & 0.9989 \\
\hline & (13) & 28.4522 & 1.3683 & 0.0038 & -0.0001 & 0.5256 & 0.6628 & 0.9990 \\
\hline \multirow{3}{*}{ Harbin (MTZ) } & (11) & 38.9948 & 1.4703 & - & - & 1.8021 & 2.0810 & 0.9995 \\
\hline & (12) & 41.7488 & 1.4689 & 0.0103 & - & 0.5701 & 0.6860 & 0.9960 \\
\hline & (13) & 41.7430 & 1.5579 & 0.0103 & -0.0002 & 0.4097 & 0.4830 & 0.9962 \\
\hline \multirow{3}{*}{ Mohe (CTZ) } & (11) & 47.1216 & 1.5402 & - & - & 2.5413 & 2.8892 & 0.9995 \\
\hline & (12) & 50.7494 & 1.5385 & 0.0136 & - & 1.0451 & 1.2842 & 0.9940 \\
\hline & (13) & 50.7418 & 1.6551 & 0.0136 & -0.0003 & 0.8702 & 1.1139 & 0.9942 \\
\hline \multirow{3}{*}{ Lhasa (TPZ) } & (11) & 27.5711 & 1.5222 & - & - & 0.8796 & 1.0273 & 0.9995 \\
\hline & (12) & 28.8263 & 1.5216 & 0.0047 & - & 0.4431 & 0.5035 & 0.9988 \\
\hline & (13) & 28.8212 & 1.5993 & 0.0047 & -0.0002 & 0.2221 & 0.2697 & 0.9989 \\
\hline
\end{tabular}




\section{Conclusions}

The optimum tilt angle plays an important role in enhancing the energy collection of solar collectors. In the present research, the monthly, seasonal, and yearly optimum tilt angles for solar collectors in six different climatic zones of China are computed using the measured weather data from China's meteorological stations over a 16-year period from 1994 to 2009, including air-dry bulb temperature, relative humidity, wind velocity, and global solar radiation data. The results show that the calculated maximum and minimum monthly optimum tilt angles are $-9.7^{\circ}$ (June, Sanya) and $78.4^{\circ}$ (December, Mohe) at six typical stations. The monthly optimum tilt angles, with Harbin as an example, are studied and analyzed. The yearly average optimum tilt angles for a south-facing solar collector are $15^{\circ}, 24.2^{\circ}, 27.4^{\circ}, 39.0^{\circ}, 47.1^{\circ}$, and $27.5^{\circ}$ in Sanya, Shanghai, Zhengzhou, Harbin, Mohe, and Lhasa, respectively. We have found that the yearly average of the optimum tilt angle is equal to the latitude of the site. This, in general, is in agreement with the results of many other researchers [13,46]. It is observed that six cities have the highest gain in solar radiation intensity when a collector is fixed at the monthly optimum tilt angle. It can be concluded that a yearly average fixed tilt angle can be used in many general applications in order to keep the manufacturing and installation costs of collectors low. For higher efficiency, the collector should be designed such that the tilt angle can easily be changed at least on a seasonal basis, if not monthly. Moreover, the general correlation equations for estimating the monthly optimum angles are developed for six stations at different climatic zones. The three proposed models are investigated using statistical indicators (including MABE, RMSE and R). The results of the statistical analysis indicate that the models in Equations (11)-(13) obtained in the paper can be used to estimate the optimum tilt angle with a high accuracy in China. These correlations can be used elsewhere with similar climatic conditions.

It is expected that the monthly, seasonal, and yearly optimum tilt angles and the general correlation equations giving optimum tilt angles generated in this paper will exert positive effects on pertinent energy-related scientific research and engineering applications in China. Future research will focus on optimum tilt angles and the general correlations on a larger regional scale; we hope to report on such works in the near future.

Acknowledgments: The research is supported by National Natural Science Foundation of China (Program No. 51507052), the China Postdoctoral Science Foundation (Program No. 2015M571653), and the Fundamental Research Funds for the Central Universities (Program No. 2015B02714). The authors also thank the China Meteorological Administration.

Author Contributions: Haixiang Zang is the principal investigator of this work. He performed the simulations and wrote the manuscript; Mian Guo contributed to the data analysis work and language editing; Zhinong Wei and Guoqiang Sun designed the simulations solution and checked the whole manuscript. All authors revised and approved the publication.

Conflicts of Interest: The authors declare no conflict of interest.

\section{References}

1. Despotovic, M.; Nedic, V. Comparison of optimum tilt angles of solar collectors determined at yearly, seasonal and monthly levels. Energy Convers. Manag. 2015, 97, 121-131. [CrossRef]

2. Stanciu, D.; Stanciu, C.; Paraschiv, I. Mathematical links between optimum solar collector tilts in isotropic sky for intercepting maximum solar irradiance. J. Atmos. Sol. Terr. Phys. 2016, 137, 58-65. [CrossRef]

3. Lunde, P.J. Solar Thermal Engineering: Space Heating and Hot Water Systems; John Wiley \& Sons Inc.: New York, NY, USA, 1980; p. 635.

4. Garg, H. Treatise on Solar Energy; John Wiley \& Sons Inc.: New York, NY, USA, 1982.

5. Erbs, D.; Klein, S.; Duffie, J. Estimation of the diffuse radiation fraction for hourly, daily and monthly-average global radiation. Sol. Energy 1982, 28, 293-302. [CrossRef]

6. Ibrahim, D. Optimum tilt angle for solar collectors used in Cyprus. Renew. Energy 1995, 6, 813-819. [CrossRef]

7. Asl-Soleimani, E.; Farhangi, S.; Zabihi, M. The effect of tilt angle, air pollution on performance of photovoltaic systems in Tehran. Renew. Energy 2001, 24, 459-468. [CrossRef] 
8. Kalogirou, S.A. Solar thermal collectors and applications. Prog. Energy Combust. Sci. 2004, 30, $231-295$. [CrossRef]

9. Kalogirou, S. The potential of solar industrial process heat applications. Appl. Energy 2003, 76, 337-361. [CrossRef]

10. Gunerhan, H.; Hepbasli, A. Determination of the optimum tilt angle of solar collectors for building applications. Build. Environ. 2007, 42, 779-783. [CrossRef]

11. Lave, M.; Kleissl, J. Optimum fixed orientations and benefits of tracking for capturing solar radiation in the continental United States. Renew. Energy 2011, 36, 1145-1152. [CrossRef]

12. Jafarkazemi, F.; Saadabadi, S.A. Optimum tilt angle and orientation of solar surfaces in Abu Dhabi, UAE. Renew. Energy 2013, 56, 44-49. [CrossRef]

13. Abdolzadeh, M.; Mehrabian, M.A. The Optimal Slope Angle for Solar Collectors in Hot and Dry Parts of Iran. Energy Sources Part A Recovery Util. Environ. Eff. 2012, 34, 519-530. [CrossRef]

14. Bakirci, K. Correlations for Optimum Tilt Angles of Solar Collectors: A Case Study in Erzurum, Turkey. Energy Sources Part A Recovery Util. Environ. Eff. 2012, 34, 983-993. [CrossRef]

15. Bakirci, K. General models for optimum tilt angles of solar panels: Turkey case study. Renew. Sustain. Energy Rev. 2012, 16, 6149-6159. [CrossRef]

16. Kaldellis, J.; Kavadias, K.; Zafirakis, D. Experimental validation of the optimum photovoltaic panels' tilt angle for remote consumers. Renew. Energy 2012, 46, 179-191. [CrossRef]

17. Kaldellis, J.; Zafirakis, D. Experimental investigation of the optimum photovoltaic panels' tilt angle during the summer period. Energy 2012, 38, 305-314. [CrossRef]

18. Pourgharibshahi, H.; Abdolzadeh, M.; Fadaeinedjad, R. Verification of computational optimum tilt angles of a photovoltaic module using an experimental photovoltaic system. Environ. Prog. Sustain. Energy 2015, 34, 1156-1165. [CrossRef]

19. Talebizadeh, P.; Mehrabian, M.; Abdolzadeh, M. Prediction of the optimum slope and surface azimuth angles using the genetic algorithm. Energy Build. 2011, 43, 2998-3005. [CrossRef]

20. Čongradac, V.; Prica, M.; Paspalj, M.; Bojanić, D.; Čapko, D. Algorithm for blinds control based on the optimization of blind tilt angle using a genetic algorithm and fuzzy logic. Sol. Energy 2012, 86, 2762-2770. [CrossRef]

21. Chang, Y.-P. Optimal the tilt angles for photovoltaic modules using PSO method with nonlinear time-varying evolution. Energy 2010, 35, 1954-1963. [CrossRef]

22. Tabet, I.; Touafek, K.; Bellel, N.; Bouarroudj, N.; Khelifa, A.; Adouane, M. Optimization of angle of inclination of the hybrid photovoltaic-thermal solar collector using particle swarm optimization algorithm. J. Renew. Sustain. Energy 2014, 6, 053116. [CrossRef]

23. Dixit, T.; Yadav, A.; Gupta, S. Optimization of PV array inclination in India using ANN estimator: Method comparison study. Sadhana 2015, 40, 1457-1472. [CrossRef]

24. Mehleri, E.D.; Zervas, P.L.; Sarimveis, H.; Palyvos, J.A.; Markatos, N.C. Determination of the optimal tilt angle and orientation for solar photovoltaic arrays. Renew. Energy 2010, 35, 2468-2475. [CrossRef]

25. Yang, H.; Lu, L. The Optimum Tilt Angles and Orientations of PV Claddings for Building-Integrated Photovoltaic (BIPV) Applications. J. Sol. Energy Eng. 2005, 129, 253-255. [CrossRef]

26. Sun, L.; Lu, L.; Yang, H. Optimum design of shading-type building-integrated photovoltaic claddings with different surface azimuth angles. Appl. Energy 2012, 90, 233-240. [CrossRef]

27. Tang, R.; Wang, J. A note on multiple reflections of radiation within CPCs and its effect on calculations of energy collection. Renew. Energy 2013, 57, 490-496. [CrossRef]

28. Liu, L.Q.; Wang, Z.X.; Zhang, H.Q.; Xue, Y.C. Solar energy development in China-A review. Renew. Sustain. Energy Rev. 2010, 14, 301-311. [CrossRef]

29. Zhao, H.; Guo, S. External benefit evaluation of renewable energy power in China for sustainability. Sustainability 2015, 7, 4783-4805. [CrossRef]

30. Lau, C.C.S.; Lam, J.C.; Yang, L. Climate classification and passive solar design implications in China. Energy Convers. Manag. 2007, 48, 2006-2015. [CrossRef]

31. Yang, L.; Lam, J.C.; Liu, J.P. Analysis of typical meteorological years in different climates of China. Energy Convers. Manag. 2007, 48, 654-668. [CrossRef]

32. Lam, J.C.; Wan, K.K.W.; Yang, L. Solar radiation modelling using ANNs for different climates in China. Energy Convers. Manag. 2008, 49, 1080-1090. [CrossRef] 
33. Argiriou, A.; Lykoudis, S.; Kontoyiannidis, S.; Balaras, C.A.; Asimakopoulos, D.; Petrakis, M.; Kassomenos, P. Comparison of methodologies for tmy generation using 20 years data for Athens, Greece. Sol. Energy 1999, 66, 33-45. [CrossRef]

34. Bulut, H. Generation of typical solar radiation year for mediterranean region of turkey. Int. J. Green Energy 2009, 6, 173-183. [CrossRef]

35. Jiang, Y.N. Generation of typical meteorological year for different climates of China. Energy 2010, 35, 1946-1953. [CrossRef]

36. Marion, W.; Urban, K. User Manual for TMY2s-Typical Meteorological Years; National Renewable Energy Laboratory: Golden, CO, USA, 1995.

37. Wilcox, S.; Marion, W. Users Manual for TMY3 Data Sets; National Renewable Energy Laboratory: Golden, CO, USA, 2008.

38. Finkelstein, J.M.; Schafer, R.E. Improved goodness-of-fit tests. Biometrika 1971, 58, 641-645. [CrossRef]

39. Zang, H.; Xu, Q.; Bian, H. Generation of typical solar radiation data for different climates of China. Energy 2012, 38, 236-248. [CrossRef]

40. Liu, B.; Jordan, R. Daily insolation on surfaces tilted towards equator. Am. Sco. Heat. Refrig. Air Cond. Eng. 1962, 67, 526-541.

41. Page, J.K. The Estimation of Monthly Mean Values of Daily Short Wave Irradiation on Vertical and Inclined Surfces from Sunshine Records for Latitudes $60^{\circ} \mathrm{N}$ to $40^{\circ} \mathrm{S}$; University of Sheffield: South Yorkshire, UK, 1976.

42. Alboteanu, I.L.; Bulucea, C.A.; Degeratu, S. Estimating Solar Irradiation Absorbed by Photovoltaic Panels with Low Concentration Located in Craiova, Romania. Sustainability 2015, 7, 2644-2661. [CrossRef]

43. Menges, H.O.; Ertekin, C.; Sonmete, M.H. Evaluation of global solar radiation models for Konya, Turkey. Energy Convers. Manag. 2006, 47, 3149-3173. [CrossRef]

44. Bulut, H. Generation of typical solar radiation data for'Istanbul, Turkey. Int. J. Energy Res. 2003, $27,847-855$. [CrossRef]

45. Bulut, H.; Büyükalaca, O. Simple model for the generation of daily global solar-radiation data in Turkey. Appl. Energy 2007, 84, 477-491. [CrossRef]

46. Benghanem, M. Optimization of tilt angle for solar panel: Case study for Madinah, Saudi Arabia. Appl. Energy 2011, 88, 1427-1433. [CrossRef]

(C) 2016 by the authors; licensee MDPI, Basel, Switzerland. This article is an open access article distributed under the terms and conditions of the Creative Commons Attribution (CC-BY) license (http://creativecommons.org/licenses/by/4.0/). 